\title{
Paid to Quit
}

\section{Robert Dur ${ }^{1,2,3}$ (D) Heiner Schmittdiel ${ }^{1}$}

Published online: 27 August 2019

(c) The Author(s) 2019

\begin{abstract}
Inspired by a recent observation about an online retail company, this paper explains why a firm may find it optimal to offer an exit bonus to recent hires so as to induce self-selection. We study a double adverse selection problem, in which the principal can neither observe agents' commitment to the job nor their intrinsic motivation. A steep wage-tenure profile deters uncommitted agents from applying. An exit bonus can stimulate that-among the committed agents - those who discovered that they are not intrinsically motivated for the job discontinue employment with the principal. Our key findings are that offering an exit bonus increases profits when the first adverse selection problem is sufficiently severe compared to the second and that the exit bonus needs to come as a surprise for the agents in order to function well.
\end{abstract}

Keywords Intrinsic motivation · Commitment $\cdot$ Self-selection · Wage compensation $\cdot$ Exit bonus $\cdot$ Transparency

JEL Classification J31 $\cdot$ J33 $\cdot$ M52 $\cdot$ M55

\section{Introduction}

Recently, an online vendor in the United States has caught attention with an unusual hiring practice; Zappos of Henderson, Nevada has been running a scheme offering all newly hired employees after their first 4 weeks a one-off payment of $\$ 4000$ if they decide to quit. According to the Chief Executive Officer (CEO) of Zappos, the idea behind this policy is to provide newcomers with an additional incentive to leave

Robert Dur

dur@ese.eur.nl

Heiner Schmittdiel

heiner.schmittdiel@gmx.de

1 Department of Economics, Erasmus University Rotterdam, Tinbergen Institute, Rotterdam, The Netherlands

2 IZA, Bonn, Germany

3 CESifo, Munich, Germany 
the company if they find out that they do not completely fit in with the corporate culture (cf. Hsieh 2010). A few other tech companies have copied the practice in the meanwhile, including Amazon, Lot18, and Riot Games (see Taylor 2014; Jeffries 2012; Edwards 2014).

Reactions to this uncommon policy have been mixed. In a Harvard Business Review Blog entry titled "Why Zappos Pays New Employees to Quit-And You Should Too", Taylor (2008) attributes the online shoe store's fast growth to the quality of their customer service. He suggests that the exit bonus has been essential in selecting the right employees for this task and recommends other companies to copy Zappos' practice: "[Offering the exit bonus is] a small practice with big implications: Companies don't engage emotionally with their customers-people do. If you want to create a memorable company, you have to fill your company with memorable people" (Taylor 2008). A Bloomberg Businessweek article is, however, more critical about Zappos' hiring practice, wondering: "[What] if hordes of people are going to start queueing up outside Zappos [...], what's to keep every young hopeful with gas money to roll in, attend part of the training, and head down the highway to the casinos with $\$ 2000$ in his pocket? It will be interesting to see what the impact of word-of-mouth will have on this odd HR process" (McFarland 2008). ${ }^{1}$

This paper explores under what conditions an exit bonus could be part of a profitmaximizing personnel policy. Our theory picks up key aspects of the two articles quoted above. We show that it can be optimal for a firm to offer an exit bonus, because it promotes self-selection of unmotivated workers out of employment, as suggested by Taylor (2008). On the other hand, this practice can be dangerous because it may attract workers without intentions to remain with the firm, as pointed out by McFarland (2008). In line with this, and consistent with Zappos' conduct, we show that the exit bonus needs to come as a surprise for workers in order to function well.

In our principal-agent model, agents differ in three respects: their commitment to the job, their outside opportunities, and their intrinsic motivation to work for the principal. All of these aspects are private information of the agents, which gives rise to two adverse selection problems. First, the principal would like to avoid hiring uncommitted agents who know beforehand that they only want to work for her for a short while. She can resolve this first problem by setting a low wage for an initial period. This, however, necessitates offering a high wage for the remaining time in order to satisfy the committed agents' participation constraint, similar to the classic model in Lazear (1979). The heterogeneity in outside options affects the severity of the first adverse selection problem and thereby influences the wage differential between periods.

At the time of application to the job, agents are already aware of the realizations of the first two dimensions of heterogeneity, namely their level of commitment and their outside opportunities. However, they only learn about their intrinsic motivation to work for the principal during the initial period. We thus follow Jovanovic (1979) in treating a job as an experience good - the only way of finding out whether the job is a good match, or in our case whether an agent is intrinsically motivated to

1 Initially, the level of the exit bonus was $\$ 2000$. Later, it was increased to $\$ 4000$. 
work in this particular job, is experiencing it. The agent's motivation cannot be readily observed by the principal. This precipitates the second adverse selection problem, because the principal prefers to retain only motivated agents. Handy and Katz (1998) and Delfgaauw and Dur (2007) show that such an adverse selection problem could be mitigated from the outset by offering a low wage so that only motivated agents find it worthwhile to apply for the job. This is, however, not possible in our setting, because the job is an experience good. Thus the overall wage profile needs to be attractive enough to convince agents to apply before it is clear to them whether they will enjoy the job. Consequently, the firm inevitably hires some agents who discover that they are unmotivated and do not enjoy the job. The principal could prompt these agents to quit by offering a lower wage once agents have discovered their motivational type. Such a policy, however, conflicts with the solution to the adverse selection problem concerning agents' commitment, which calls for a steep wage-tenure profile. As a result, unmotivated agents may, despite their lack of motivation, find it in their best interest to stay at the firm if the wage profile is sufficiently steep. A solution to this problem is offering an exit bonus after the initial period, which persuades unmotivated agents to quit. We show that such an exit bonus is part of a profit-maximizing personnel policy if solving the first adverse selection problem necessitates a sufficiently steep wage profile and if intrinsic motivation plays a comparatively minor role.

As pointed out by McFarland (2008), the exit bonus may attract uncommitted agents. Our analysis validates this concern: we find that the exit bonus can only be a viable instrument if it is kept secret ex ante. This is so because it would be a perfect substitute for the wage-tenure profile if it were anticipated. Hence, the principal cannot resolve both adverse selection problems anymore if agents take into account that they will be offered an exit bonus later on. Consistent with this, Zappos does not advertise the exit bonus. While Zappos does confirm its practice in interviews and on its website, these sources are directed at interested outsiders rather than potential future employees. Most importantly, there is no mention of the exit bonus in job descriptions or on the recruitment website (see e.g. Zappos 2013a; the same holds for the companies that copied Zappos' policy that we mention above).

The remainder of the paper is structured as follows. The next section provides an overview of the related literature. Section 3 describes the model. Results are presented and discussed in Sect. 4, followed by a concluding section.

\section{Related Literature}

The recent attention Zappos and others have received for their practice to pay an exit bonus (cf. Taylor 2008, 2014; McFarland 2008; Jeffries 2012; Edwards 2014) suggests it is an uncommon, perhaps surprising, policy. We do agree with this notion and only know of a handful of firms using such an instrument. Then again, our theory predicts that it should not be advertised, so not knowing about firms using an exit bonus may simply be due to the fact that they try to keep such practices in the dark. Nonetheless, another closely related phenomenon can be observed in compensation packages, most prominently in those of executive officers: severance 
pay. Crucial differences between the exit bonus offered by Zappos and severance pay packages are that the former is offered to all recent hires to stimulate voluntary quits, while the latter are incidentally granted upon involuntary departure of employees. A commonly used term for severance pay in executive contracts is the Golden Parachute, whereas a Golden Handshake labels severance pay that is awarded on a discretionary basis. Theoretical literature on severance pay explains why it may arise in a principal-agent setting and what the welfare implications of its introduction are.

Lazear (1990) analyzes effects of a state-mandated severance pay on the labor market. His theoretical prediction is that compulsory severance pay should not matter in a frictionless world: in a competitive labor market, employers will require workers to pay a fee upfront to offset the expected severance pay. However, this result may be nullified by, for example, restrictions on the borrowing and lending opportunities of employees. Lazear's (1990) empirical analysis of a 22-country panel suggests that the introduction of severance pay requirements indeed leads to a lower employment rate.

Rather than from legal coercion, severance pay may emerge voluntarily for several reasons. Much of the theoretical literature incorporates the idea that a riskneutral principal offers a form of insurance against unstable income to risk-averse agents. This insurance may be provided either by a contract with guaranteed employment (Baily 1974; Gordon 1974; Azariadis 1975; Akerlof and Miyazaki 1980) or by a contract that warrants severance pay in case of a layoff (Grossman and Hart 1981; Hart and Holmstrom 1987; Pissarides 2001; see Parsons 2019 for a discussion of the differences between these two types of insurance). In fact, a focus in this research has been set on explaining why such insurance is not offered more extensively (see for example Kahn 1985; or Ito 1988). Similar to the insurance argument, Booth and Chatterji (1989) develop a model in which a worker who partially bears the cost of firm-specific training requires to be compensated in case of dismissal. It is important to note that the exit bonus we study is only paid after a voluntary quit, not if the employee is fired. As such, it does not provide insurance against unemployment. Furthermore, if it were offered for insurance reasons, it would be advertised and made part of the contract ex ante rather than come as a surprise. ${ }^{2}$

Another reason why severance pay could be observed lies in a change of outside opportunities of the agent. Lazear (1981) considers a setup where principals incentivize agents to exert effort with a steep wage-tenure profile. A situation may arise where agents are paid above their marginal product towards the end of their careers.

\footnotetext{
2 According to Yermack (2006), severance pay to CEOs is most often granted in the form of a Golden Handshake. He adds to the insurance argument, possibly in the form of an implicit contract: "In cases of risk aversion or effort avoidance, CEOs would be more likely to pursue value maximizing strategies due to the security provided by severance pay" (p. 241). In the case of Golden Parachutes, severance pay can help to make sure that a CEO does not prevent a take-over of the firm that is in the interest of the shareholders (cf. Lambert and Larcker 1985). On top of this, Yermack (2006) offers three more reasons for paying a departing executive: rent extraction - a powerful manager may be able to expropriate shareholders; ex post settling up — severance pay may be used to compensate a successful CEO at the end of his career for being underpaid before; and damage control—severance pay may be made in exchange for a confidentiality or non-litigation agreement by the manager. None of these arguments seem to bear much relevance in our context.
} 
When an agent receives an unanticipated outside offer, the principal may choose to offer a one-off payment for efficient separation in lieu of the above-productivity wage. Note that this payment is made after a voluntary quit, a situation quite similar to that considered in our model. There are two crucial differences though. First, the exit bonus in our model needs to come as a surprise, whereas in Lazear's (1981) model it pays off for the principal to announce that severance pay may be offered after a shock to the agents' outside options. This is so because the anticipation of a possible severance payment would make it easier to convince the agent to accept the job. Second, the severance pay in Lazear (1981) would only occur for agents who are in the later stages of their careers, whereas the exit bonus that we study is offered to new hires.

Other papers have studied a scenario where a change of market conditions makes an employer want to reduce the number of employees. Sometimes, simply firing employees is not possible or prohibitively costly, for example in the public sector, in markets with strong labor rights, or where (potential) customers may be strongly opposed to large layoffs. Levy and McLean (1996), Jeon and Laffont (1999), and Rama (1999) deal with the question of how to reduce the work force in such a situation and all include a form of severance pay in their analyses. ${ }^{3}$

The paper that comes closest to our approach is that of Inderst and Mueller (2010), who consider the effect of Golden Parachutes on information revelation by CEOs. As mentioned above, such agreements are usually only put into effect upon involuntary departure. Inderst and Mueller (2010), however, argue that the replacement of a CEO must be incentive compatible for him, because he is often the only person that could disclose information to the board that would lead to his termination. As such, severance pay may be used as a tool to make CEOs reveal when they are a bad match to the firm, in which case they would be fired. The central finding of their theoretical paper is that steep incentive pay may be a less costly instrument to this end than severance pay. Our approach differs from Inderst and Mueller's (2010) in four ways: First, we assume that the principal cannot make use of a performance measure, thus there is no way to implement an incentive pay scheme. Instead, the agent's utility is linked to the principal's profits through intrinsic motivation to exert effort. ${ }^{4}$ Second, our model incorporates an additional adverse selection problem at the moment of hiring. We argue that uncommmitted agents must be deterred from applying, a problem that is less of an issue when hiring a CEO, as more information about him is available to the principal. Third, Inderst and Mueller (2010) impose a limited liability constraint, which is not necessary in our setup. Fourth, we find that the exit bonus needs to be a secret at the time of hiring.

Finally, our work relates to an emerging literature arguing that full transparency of personnel policies can be suboptimal. Jehiel (2015) shows that it can pay off for a firm to leave workers in the dark concerning what performance measures they will be evaluated on, how their coworkers' incentive schemes are set up, and what exactly the production function of the firm is. He finds that non-transparency

\footnotetext{
3 See also Foarta and Sugaya (2019) for a related study in the context of "acqui-hiring".

4 As we shall argue in the next section, this fits well with the case of Zappos.
} 
becomes advisable as soon as the dimensionality of moral hazard problems is larger than that of one agent's action space. The idea behind this is that it may be cheaper for the principal to resolve several moral hazard problems with one single incentive constraint. In simple words, if a worker knows his performance will be assessed, but does not know how, he might exert more effort (see also Lazear 2006; Ederer et al. 2018 for related arguments). Likewise, Von Thadden and Zhao (2012) find that it can be a good idea to offer incomplete contracts concerning the agent's action space, arguing: "if [...] the employee is unaware of some shirking behavior, then it may not be optimal [...] to regulate this kind of activity in the contract, since this makes [him] aware of the activity and necessitates the provision of costly incentives" (p. 1152).

\section{The Model}

Our model features two periods: Period 1 consists of one term, whereas Period 2 consists of $n$ terms. At the beginning of Period 1, the principal can hire particular agents if she offers a wage profile that satisfies their participation constraint and deter other types of agents from applying with a wage profile that violates their constraint. Agents differ along three dimensions (commitment, motivation, and outside option), none of which is readily observable to the principal. The principal's payoff increases in an agent's effort and decreases in his compensation. Agent $i$ 's utility in term $t$ when employed by the principal is given by:

$$
U_{i t}=w_{t}+f_{i}\left(e_{i t}\right),
$$

where $w_{t}$ denotes the wage, and $f_{i}\left(e_{i t}\right)$ captures the impact on utility of effort $e_{i t}$ that the agent exerts when working for the principal. We avail ourselves of the following functional form:

$$
f_{i}\left(e_{i t}\right)=\gamma_{i} e_{i t}-\frac{1}{2} \theta e_{i t}^{2}
$$

which allows for agents to experience a certain joy of work, as long as their motivation parameter $\gamma_{i}$ is positive. A key assumption in our paper is that agents only learn the value of their motivation parameter by working for the principal for one term. Ex ante, the agent only knows he can be the motivated type, with $\gamma=\bar{\gamma}>0$, or the unmotivated one, with $\gamma=0$; these two cases can occur with probabilities $0<q<1$ and $1-q$, respectively. Motivated agents' incentives are thus partially aligned with those of the principal, because they enjoy exerting effort to some extent, as in e.g. Benabou and Tirole (2003), Besley and Ghatak (2005), and Delfgaauw and Dur (2007). The principal in our model has no means of monitoring effort. ${ }^{5}$ Hence, an agent's pay or retainment cannot be conditioned on his effort. The principal can commit to a wage-tenure profile and, if she wishes, to offering an exit bonus.

\footnotetext{
5 We also assume that the principal cannot contract on a noisy effort measure, like performance. As a matter of fact, Zappos explicitly condemns performance measures; the reasoning behind this is that employees are supposed to deliver better work, e.g. a friendlier customer service, when they are not monitored and can act freely (Hsieh 2010).
} 
When not working for the principal, agents derive per-term utility $V_{i}$, posing another source of heterogeneity. We allow the outside option utility of agents to be $\bar{V}$ or $\underline{V}$, with $\bar{V}>V$. The principal has the opportunity to augment the outside option of her agents in Period 2 by offering an exit bonus $b$. We rule out indentured servitude; that is, we assume that $b \geq 0$. Furthermore, we assume that the exit bonus comes as a surprise to agents if the principal decides not to advertise it. Finally, agents differ in their commitment to the principal: uncommitted agents know for sure they are looking for employment with the principal for Period 1 only, whereas committed agents are potentially interested to work for both periods. We assume that the principal wants to avoid hiring uncommitted agents, for example because of training and other turnover costs.

The sequence of events is as follows:

1. Nature draws types.

2. The principal designs a compensation plan consisting of a first period wage, a second period wage, and possibly an exit bonus, and decides whether to advertise the exit bonus or not.

3. Agents decide whether to apply for a job with the principal.

4. Agents are hired and make an effort choice for the first period, during which they learn about their intrinsic motivation to work for the principal. The first period wage is paid out.

5. The principal decides whether to offer an exit bonus or not.

6. Agents decide whether to quit or continue working for the principal. Those who quit enjoy their second period outside option utility and, if it was offered in Stage 5 , the exit bonus.

7. Agents who continue make an effort choice for the second period and receive the second period wage.

\section{Analysis}

We solve the model by backward induction.

\subsection{Period 2}

At the start of Period 2, each employed agent needs to decide on whether to continue employment with the principal or to quit, which may depend on his realization of motivational type. The agent has learned his type in Period 1, so in case he stays at the firm, makes his effort choice according to whether or not he is motivated. The unmotivated agent derives utility:

$$
U_{i 2}=n\left(w_{2}+0-\frac{1}{2} \theta e_{i 2}^{2}\right),
$$

so he has no reason to put in effort:

$$
e_{i 2}=0 \text {. }
$$

The motivated agent on the other hand maximizes: 


$$
U_{i 2}=n\left(w_{2}+\bar{\gamma} e_{i 2}-\frac{1}{2} \theta e_{i 2}^{2}\right),
$$

which yields the following optimal effort level:

$$
e_{i 2}=\frac{\bar{\gamma}}{\theta}
$$

Agents decide on whether to continue employment with the principal based on the realization of their motivation parameter and the wage the principal offers, compared to their outside opportunities. In the absence of an exit bonus, which will be introduced in Sect. 4.3, a motivated agent stays iff:

$$
n\left(w_{2}+\frac{\bar{\gamma}^{2}}{2 \theta}\right) \geq n V_{i} .
$$

An unmotivated agent, who earns no motivational rents, continues iff:

$$
n w_{2} \geq n V_{i}
$$

Hence, the principal should offer $w_{2}<V_{i}$ in order to induce all unmotivated agents with at most outside option utility $V_{i}$ to quit. As we shall see in Sect. 4.3, this solution to the adverse selection problem regarding agents' motivation sometimes conflicts with solving the adverse selection problem regarding agents' commitment to the job.

\subsection{Period 1}

At the start of Period 1, agents need to decide whether they find it worthwhile to apply for the job offered by the principal. This decision is based on the expected utility in Period 2, the effort choice in Period 1, and the wage profile offered by the principal.

When the agent starts working for the principal, he does not know what motivational type he is. Since effort is not monitored, effort in Period 1 has no effect on the agent's expected utility in Period 2, other than through learning his motivational type (which happens for any $e_{i 1}>0$ ). Hence, an agent will choose a level of effort that maximizes his expected utility in Period 1, which is described by:

$$
\begin{aligned}
\mathbb{E} U_{i 1} & =w_{1}+q\left(\bar{\gamma} e_{i 1}-\frac{1}{2} \theta e_{i 1}^{2}\right)+(1-q)\left(0-\frac{1}{2} \theta e_{i 1}^{2}\right) \\
& =w_{1}+q \bar{\gamma} e_{i 1}-\frac{1}{2} \theta e_{i 1}^{2} .
\end{aligned}
$$

Utility maximization yields:

$$
e_{i 1}=q \frac{\bar{\gamma}}{\theta}
$$

Comparing this result to the effort choices in Period 2, where agents are aware of their type, it can be seen that the effort choice of the uncertain agent lies in between 
that of an unmotivated agent, $e_{i 2}=0$, and that of a motivated agent, $e_{i 2}=\frac{\bar{\gamma}}{\theta}$. The higher the probability of being a motivated agent, $q$, the more effort will be provided to reap the benefits of that possibility.

Applying at the firm is beneficial to an agent if his expected utility from having the job exceeds his opportunity costs. The agent is aware of his outside option $V_{i}$ and knows whether he is uncommitted, i.e. he wants to work in Period 1 only. Using Eqs. (3) and (4), it follows that uncommited agents can be deterred from applying iff:

$$
\mathbb{E} U_{1} \leq V_{i} \Longleftrightarrow w_{1}+\frac{q^{2} \bar{\gamma}^{2}}{2 \theta} \leq V_{i} .
$$

Hence, the wage in the first period should be sufficiently low, as in Lazear (1979). Committed agents decide to apply iff:

$$
\begin{aligned}
\mathbb{E} U_{1}+\mathbb{E} U_{i 2} \geq & (1+n) V_{i} \\
& \Longleftrightarrow w_{1}+\frac{q^{2} \bar{\gamma}^{2}}{2 \theta}+n\left(q\left(w_{2}+\frac{\bar{\gamma}^{2}}{2 \theta}\right)+(1-q) \max \left\{V_{i}, w_{2}\right\}\right) \\
\geq & (1+n) V_{i},
\end{aligned}
$$

where we have substituted the optimal effort levels described in Eqs. (1), (2), and (4). Note that Condition (5) implies that, quite naturally, we focus on a case in which the contract is designed such that agents who find out that they are motivated expect to continue employment with the principal. ${ }^{6}$ The unmotivated agents on the other hand may choose to quit, but only if their outside option is higher than the wage paid by the principal in Period 2.

\subsection{Contract Design}

In this subsection we focus on the most interesting case where the principal wants to deter all-that is, irrespective of their outside options-uncommitted agents from applying and wants to attract all committed agents. We deal with other possible cases in Sect. 4.4.

The adverse selection problem regarding agents' commitment is resolved when the participation constraint of the uncommitted agents with low outside options is violated (the participation constraint of the uncommitted agents with high outside options is then violated too). Hence, the principal sets ${ }^{7}$ :

\footnotetext{
${ }^{6}$ This is consistent with the principal's aim to deter uncommitted agents, because she wants (some) agents to continue employment into Period 2. Note that, if Condition (5) is satisfied, motivated agents prefer to continue: when the second period wage is designed to make an agent apply for the job before he knows whether he is motivated, he will be happy to continue once he learns that he will earn motivational rents.

${ }^{7}$ To be sure, the principal could of course also set a lower wage in the first period, and adapt the second period wage to compensate for this. This does not affect our key results qualitatively.
} 


$$
w_{1}=\underline{V}-\frac{q^{2} \bar{\gamma}^{2}}{2 \theta}
$$

That is, she must make sure the wage in Period 1 does not exceed the lower one of the outside options, $\underline{V}$, net of the expected motivational rent in the first period $\frac{q^{2}{ }^{2}}{2 \theta}$. Similarly, the participation constraint for all committed agents will be satisfied when it is satisfied for the committed agents with a high outside option:

$$
w_{1}+\frac{q^{2} \bar{\gamma}^{2}}{2 \theta}+n\left(q\left(w_{2}+\frac{\bar{\gamma}^{2}}{2 \theta}\right)+(1-q) \max \left\{\bar{V}, w_{2}\right\}\right) \geq(1+n) \bar{V}
$$

We need to distinguish two cases. We will later derive the conditions under which each case becomes relevant. In the first case, when Eqs. (6) and (7) imply $w_{2}<\underline{V}$, all unmotivated agents quit after Period 1 and the second period wage is set at:

$$
w_{2}=\bar{V}-\frac{\bar{\gamma}^{2}}{2 \theta}+\frac{\bar{V}-\underline{V}}{n q} .
$$

That is, the second period wage, which is paid $n q$ times in expected terms, needs to compensate for the outside option $\bar{V}$, but can extract the motivational rents $\frac{\bar{\gamma}^{2}}{2 \theta}$, while compensating for the relatively low wage in the first period.

In the second, more interesting, case, where Eqs. (6) and (7) necessitate $w_{2}>\bar{V}$, all agents expect to stay, even those who have discovered in Period 1 that they are unmotivated. ${ }^{8}$ The second period wage needed to attract all committed agents reads:

$$
w_{2}=\bar{V}-\frac{q \bar{\gamma}^{2}}{2 \theta}+\frac{\bar{V}-\underline{V}}{n},
$$

which, together with the condition $w_{2}>\bar{V}$, implies that for this case to occur, it must hold that:

$$
\bar{V}-\underline{V}>n q \frac{\bar{\gamma}^{2}}{2 \theta}
$$

Very similar to Eq. (8), the second period wage in this more interesting case, as described by Eq. (9), compensates for the outside option, extracts motivational rents, and compensates for the low wage in Period 1. The only difference is that it accounts for the fact that now all, even the unmotivated, agents expect to receive it. Rather than extracting full motivational rents as in the case where only motivated agents expect to continue, it extracts the expected motivational rents. Likewise, the compensation for the low first period wage does not need to be as high, because the expected duration of employment is longer. In this second case, even the unmotivated agents prefer to remain employed by the principal, the second adverse selection problem. It occurs because the second period payoff exceeds the outside option,

\footnotetext{
${ }^{8}$ We treat the third case, where $V<w_{2}<\bar{V}$, in the next subsection.
} 
even in the absence of motivational rents. Recall that the principal cannot solve this problem by reducing the second period wage in exchange for an increase in the first period wage, as this would contravene the solution to the first adverse selection problem described by Eq. (6).

The principal can overcome the adverse selection problem by offering a one-off payment to all employees who quit at the start of Period 2, the exit bonus $b$. In order for it to induce unmotivated agents to leave, it needs to violate their continuation constraint. She can offer a relatively low exit bonus such that only the unmotivated agents with high outside opportunities quit, or a higher one that also induces those with low outside opportunities to leave. We will first analyze the implications of a relatively low exit bonus. Unmotivated agents with high outside opportunities will quit if the exit bonus is set such that:

$$
n w_{2} \leq n \bar{V}+b \Longleftrightarrow b \geq n\left(w_{2}-\bar{V}\right)
$$

When this condition is set binding, some unmotivated agents will self-select and quit, while all motivated agents will continue because of the motivational rents they earn. Substituting Eq. (9) into Eq. (11) gives after some rewriting:

$$
b=\bar{V}-\underline{V}-n q \frac{\bar{\gamma}^{2}}{2 \theta} .
$$

Offering this exit bonus increases the principal's profits by $n w_{2}-b=n \bar{V}$ for each unmotivated worker who quits. ${ }^{9}$ Note that Eq. (12) implies a strictly positive exit bonus whenever the second adverse selection problem occurs, namely when Condition (10) holds. The outside option dispersion $\bar{V}-\underline{V}$ is a representation of the severity of the first adverse selection problem. If it is $\overline{l a r g e}$, it is relatively hard to attract all committed agents while deterring all uncommitted agents, thus requiring a steeper wage profile. This is so because $w_{1}$ increases in $\underline{V}$, whereas $w_{2}$ decreases in it, while increasing in $\bar{V}$ [see Eqs. (6) and (9)]. Only if this outside option dispersion is larger than the expected motivational rents earned in Period 2, an exit bonus is useful. This case becomes less likely when the probability of being the motivated type $q$ or the duration of the second period $n$ increases. The intuition is that higher expected motivational rents enable the principal to offer a lower second period wage, thus discouraging the unmotivated agents to stay. Note that the principal would prefer to pay a negative exit bonus when Condition (10) is violated, that is unexpectedly charge agents who want to quit. We rule this out, however, by not allowing the principal to deprive agents of their freedom to leave, i.e. $b \geq 0$.

The principal may also choose to offer a higher exit bonus such that all unmotivated agents quit. This can be achieved by satisfying the following condition:

$$
b \geq n\left(w_{2}-\underline{V}\right) .
$$

\footnotetext{
${ }^{9}$ Recall that unmotivated workers do not exert effort and, therefore, do not produce any valuable output for the principal.
} 
Once again setting this condition binding and substituting Eq. (9) yields the following expression:

$$
b=(1+n)(\bar{V}-\underline{V})-n q \frac{\bar{\gamma}^{2}}{2 \theta} .
$$

Offering this exit bonus results in an increase in the principal's profits of $n w_{2}-b=n \underline{V}$ for each unmotivated worker who leaves. ${ }^{10}$ Quite naturally, this exit bonus deterring all unmotivated agents from staying exceeds the one in Eq. (12) by exactly $n$ times the dispersion in outside opportunities. This is problematic, however, because such a high exit bonus may also induce some motivated agents to quit. Indeed, motivated agents with high outside opportunities quit if:

$$
b \geq n\left(w_{2}+\frac{\bar{\gamma}^{2}}{2 \theta}-\bar{V}\right) .
$$

Using Eqs. (9) and (14), one can see that this condition is met whenever $\bar{V}-\underline{V} \geq \frac{\bar{\gamma}^{2}}{2 \theta}$. It follows that, keeping in mind Condition (10), the high exit bonus to deter all unmotivated agents from staying can only be implemented without losing any motivated agents when $n q<1^{11}$

In summary, we have derived an expression for the first period wage that solves the adverse selection problem regarding agents' commitment to the job. In order to satisfy the participation constraint of the committed agents, a certain second period wage needs to be offered. Depending on parameters, this wage profile may lead to an adverse selection problem concerning agents' motivation. We have shown that an exit bonus can alleviate the second adverse selection problem.

As long as no motivated agents are encouraged to quit by an exit bonus, it is clearly optimal to offer it. This is so because the unmotivated agents' optimal effort choice is $e_{i 2}=0$, yielding no production. Under this assumption it follows immediately from Eq. (11) that it is more profitable for the principal to induce some unmotivated agents to quit by offering the exit bonus, amounting to costs of $n\left(w_{2}-\bar{V}\right)$, rather than keeping them and paying out the second period wage $n$ times, amounting to $n w_{2}$. The same holds for the exit bonus described by Condition (13), provided that Condition (15) is violated so that motivated agents do not quit.

Generally speaking, the exit bonus could serve as a form of insurance for the agents against the possibility to turn out unmotivated. Since this benefits the agents,

\footnotetext{
10 Note that this is a smaller amount than in the case of the lower exit bonus analyzed above. However, more unmotivated workers will accept the offer, which may render the higher exit bonus a more profitable alternative.

11 If $n q>1$, designing a contract with a high exit bonus is not profit-maximizing in our framework for the following reason. Our analysis rests on the assumption that the principal is in need of motivated agents for Period 2. If she were not interested in keeping the motivated agents with high outside opportunities, she could have deterred all agents with high outside opportunities from the very beginning by offering a lower second period wage (see Sect. 4.4).
} 
announcing the exit bonus should enable the principal to save on the wages that need to be offered. ${ }^{12}$ However, if the exit bonus were announced, the uncommitted agents could only be deterred from applying if the first period wage is even lower, namely taking into account that they will always take advantage of the exit bonus after working for the first period. Naturally, this requires that the principal set an even higher second period wage such that committed agents find it worthwhile to apply despite the low first period wage. Such a high second period wage would in turn necessitate an increase in the exit bonus in order to induce unmotivated agents to quit, requiring yet another decrease in the first period wage and so forth. Since the exit bonus and the first period wage are perfect substitutes for the uncommitted agents, it follows that the principal cannot solve both adverse selection problems once that agents anticipate an exit bonus. A formal exposition of this argument is contained in the "Appendix" section. The important conclusion is that the exit bonus needs to come as a surprise, and hence should not be advertised, in order to function well.

\subsection{Other Cases}

The previous section has been confined to the most interesting case where the principal wants to hire all committed agents and none of the uncommitted agents at the start of the first period, and where either all or none of the unmotivated agents expect to quit at the beginning of the second period. Here we briefly deal with the other possible cases.

First, we have so far disregarded the case where $\underline{V} \leq w_{2} \leq \bar{V}$. It implies that agents who find out that they are unmotivated will quit when they have high outside opportunities, but expect to stay when their outside option is low. Maintaining the assumption that the principal wants to attract all committed agents, she chooses to offer such a second period wage for a certain parameter interval. As in the previous subsection, the conditions on parameters can be found by substituting the second period wage. ${ }^{13}$ After some rewriting, this yields:

$$
\frac{n q}{n q+1} \frac{\bar{\gamma}^{2}}{2 \theta} \leq \bar{V}-\underline{V} \leq n q \frac{\bar{\gamma}^{2}}{2 \theta} \text {. }
$$

When the principal is in this situation she may choose to offer an exit bonus in order to also induce unmotivated agents with low outside opportunities to quit. Naturally, the principal will offer it after the unmotivated agents with high outside options have left already. It should then be set at:

$$
b=\frac{1+n q}{q}(\bar{V}-\underline{V})-n \frac{\bar{\gamma}^{2}}{2 \theta} .
$$

\footnotetext{
12 Note that both the principal and the agents are risk-neutral towards income, so insurance could not lead to a Pareto improvement. Nonetheless, by offering the exit bonus the principal incurs expenses that are beneficial to the agents, so she should be able to extract these benefits by offering lower wages.

13 Note that the expression for the second period wage to be used is the same as in Eq. (8), the first case treated in the previous subsection.
} 
Note that, again, this exit bonus may prompt some motivated agents to quit. As before, the condition for some motivated agents to quit under this exit bonus would be $\bar{V}-\underline{V}>\frac{\bar{\gamma}^{2}}{2 \theta}$.

Second, in all cases treated so far, the principal could increase the exit bonus to a level that prompts some, or even all, motivated agents to quit after Period 1. As noted in the previous subsection, this would conflict with the assumption that the principal is in need of motivated agents for Period 2. If she were not interested in employing all motivated agents in Period 2, but only those with low outside opportunities, she can offer a wage profile that circumvents the adverse selection problem regarding agents' motivation. It would consist of a first period wage as described by Eq. (6) and a second period wage that is sufficient to induce the motivated agents with low outside opportunities to stay:

$$
w_{2}=\underline{V}-\frac{\bar{\gamma}^{2}}{2 \theta} \text {. }
$$

When offering this second period wage, agents who find out they are not motivated prefer to quit and no exit bonus is needed.

Third, the principal may wish to tolerate some uncommitted agents in the first period. She will already attract uncommitted agents with low outside opportunities by marginally increasing the first period wage. As a consequence, she could decrease the second period wage while still making the committed agents apply. This, however, gives the adverse selection concerning agents' motivation less bite, so the exit bonus can also be decreased. This process could be continued until the exit bonus reaches its natural downward boundary $b=0$. Thus, when allowing for some uncommitted agents to apply, she can alleviate the adverse selection problem concerning agents' motivation the same way the lower exit bonus would do by offering a simple flat wage:

$$
w_{1}=w_{2}=\bar{V}-\frac{q^{2}+n q}{1+n q} \frac{\bar{\gamma}^{2}}{2 \theta} .
$$

Note that at this wage profile, uncommitted agents with high outside opportunities still prefer not to apply.

Last, the principal may wish to hire all agents at the start of the first period. The principal can do so by offering a first period wage marginally above:

$$
w_{1}=\bar{V}-\frac{q^{2} \bar{\gamma}^{2}}{2 \theta}
$$

The following second period wage is then sufficient to retain all motivated agents:

$$
w_{2}=\bar{V}-\frac{\bar{\gamma}^{2}}{2 \theta} \text {. }
$$

Note that this is less than what is paid in the first period. It is just sufficient to keep the motivated agents with high outside opportunities from leaving the principal. At the same time, it may convince all unmotivated agents to quit, namely when $\bar{V}-\underline{V}<\frac{\bar{\gamma}^{2}}{2 \theta}$. The optimal scheme for the principal will eventually depend on these parameters, the costs associated with employing uncommitted agents, and the relative mass of agents with high or low outside opportunities. 


\subsection{Discussion}

The key findings of our analysis are twofold. First, using an exit bonus is only optimal when the outside option dispersion is large and intrinsic motivation plays a comparatively minor role. The intuition behind this finding is that keeping out uncommitted agents necessitates a steep wage profile, in which the wage difference is driven by the dispersion in outside options. Returning to our motivating example of Zappos, one could hypothesize that the supply of uncommitted labor is particularly high in a vice industry-driven economy like Nevada's (see e.g. The Economist 2010).

The adverse selection problem regarding agents' motivation, on the other hand, only becomes pertinent when the wage difference between periods is large compared to the difference in motivation. Zappos does not offer a salary increase right after training; however, it has been growing rapidly over the last years and has thus been able to offer career opportunities that may act in lieu of wage increases (cf. Lazear 1979; Witkin 2012; Geron 2009).

The economics literature on intrinsic motivation typically does not focus on low skilled, repetitive jobs like those of a customer service representative. Taylor (2008), however, suggests that Zappos has created a work environment in which motivation plays a role. This relates to its policy of avoiding performance measurement with the tools common to this industry in favor of having motivated, empowered employees (cf. Hsieh 2010). While Zappos reportedly creates a pleasant work environment (see e.g. Fortune 2012; Glassdoor 2013), the actual tasks of working in customer service have been shown to be emotionally exhausting (cf. Singh et al. 1994), giving rise to the notion that a motivated employee may enjoy the job not much more than an unmotivated employee.

So far, we have only considered the potential effect of the pleasant working conditions at Zappos on workers' intrinsic motivation. It may, however, very well be that some people do find out that they enjoy working at this firm, but at the same time are not inclined to exert effort. As a consequence, even an employee who finds out to be unmotivated may, in view of the career opportunities or the pleasant work environment at Zappos, prefer to remain in the firm. In line with the predictions of our model, this would be a situation where an employer finds it profit increasing to offer an exit bonus.

Second, we predict that the exit bonus needs to come as a surprise to the agents in order to function well. The question of whether or not potential applicants do anticipate that Zappos may offer an exit bonus is an empirical one. We do, however, have reason to believe the exit bonus is not commonly anticipated. While Zappos does confirm the existence of the exit bonus publicly (see e.g. Hsieh 2010; Zappos 2013b), these sources are directed at interested outsiders rather than potential future employees. Most importantly, there is no mention of the exit bonus in job descriptions or on the recruitment website (see e.g. Zappos 2013a). Another indication that McFarland's (2008) concern about word-of-mouth has not (yet) materialized is that the exit bonus is only accepted by a one-digit percentage of new hires (see e.g. Hsieh 2010; Zappos 2013b). If the exit bonus were anticipated by a large fraction 
of the local labor force, one would expect this number to be higher, despite Zappos' screening efforts.

Furthermore, we have made some conjectures concerning the production function of the firm and concerning conditions in the labor market that lead to the emergence of an exit bonus. Zappos asserts to be interested in its employees remaining in the firm for long periods (cf. Geron 2009), a fact that supports the notion that it is costly to grant short-term employment, which is the reason why the principal in our model chooses to deter uncommitted agents from applying. Our model shows that a profitmaximizing principal in need of some new motivated agents may hire agents with low outside opportunities and design a flat wage that will prompt agents who find out that they are unmotivated to quit. If, however, the principal is in need of many new motivated agents, ${ }^{14}$ the second period wage needed is "too high", such that an exit bonus emerges. We believe a fast growing firm with a pronounced emphasis on customer service like Zappos fits this scenario very well.

\section{Concluding Remarks}

We have put forward a model that shows under which circumstances a firm may find it optimal to use exit bonuses to convince intrinsically unmotivated employees to quit. We have shown that such a situation may arise when a firm offers a steep wage profile, in our example due to an adverse selection problem caused by potential job applicants with a short horizon. In particular, this problem needs to be severe in comparison to the expected motivational rents earned during an applicant's career. As a consequence, an exit bonus is more likely to be offered when potential applicants do not expect to enjoy working in this particular job too much.

Alternative explanations as to why we observe the exit bonus appear to fail. For example, the exit bonus may be used by an employer to signal that employees can earn motivational rents when working for her, rather than as a means to solve the adverse selection problem concerning agents' motivation. However, in that case, we would expect Zappos to advertise the exit bonus actively. The same is true when exit bonuses are used to solve a commitment problem on the side of the employer. For instance, an employer may be able to commit to creating a pleasant work environment by offering an exit bonus. The first adverse selection problem that we identified may apply here too, making advertised exit bonuses not profit-maximizing.

Indeed, our analysis suggests that an exit bonus must not be advertised. As such, the exit bonus may be considered an out of equilibrium phenomenon. If offering it became a common HR practice, our model predicts that it would no longer have the desired effect. One would have to expect an influx of uncommitted applicants who are (only) interested in receiving the exit bonus after a short training period. This would require increasing screening efforts by HR departments to filter out such job candidates which — at least in some environments — may not be feasible or prohibitively costly.

\footnotetext{
14 Note that the satisfaction of this need comes hand in hand with the necessity to tolerate some unmotivated agents in the second period, unless $n q<1$.
} 
An analogy to the dynamics described above can be found in a rather delicate area: In 2012, Switzerland started to offer Tunisian asylum seekers money if they decide to return to their country of origin (cf. NZZ 2012). ${ }^{15}$ Applications for asylum from Tunisian citizens are rarely accepted in the Swiss Confederation and refugees are only eligible for the "return assistance" before their application for asylum has been decided on. It could be argued that the information structure in this example is comparable to that in our model. Applicants have private information on their chances to receive refugee status, and are willing to await the ruling in the relatively bad living conditions of an asylum seeker (cf. Hatton 2004). If offered money upon return, some applicants may decide to return, namely those who are relatively "unmotivated", because they deem their chances of being accepted as low. Just as in our setup, it is crucial that this policy is not widely known. Otherwise, one could expect refugee numbers to rise, or even non-immigrants starting to apply for asylum in the hope of receiving a return assistance.

The motivation to develop the model presented in this paper originated in an observation of one single firm. Even though several other firms have followed Zappos' lead in the meanwhile, this could raise concerns about the relevance of the HR policy we analyze. We can, however, conceive a few arguments to put the scarcity of observations into perspective. While it is of course possible that using an exit bonus is not profit maximizing, our model yields conditions under which its use would be the optimal strategy. It may be that these conditions are just not satisfied at other firms. Secondly, other firms may simply not be aware of this innovation in compensation policies. This is supported by the attention that Zappos and the other tech firms' conduct has received in the business press. ${ }^{16}$ Finally, a key result of our analysis is that the exit bonus needs to come as a surprise. In light of this, it may very well be that firms use tools such as exit bonuses without outsiders knowing about it.

Open Access This article is distributed under the terms of the Creative Commons Attribution 4.0 International License (http://creativecommons.org/licenses/by/4.0/), which permits unrestricted use, distribution, and reproduction in any medium, provided you give appropriate credit to the original author(s) and the source, provide a link to the Creative Commons license, and indicate if changes were made.

\section{Appendix}

In Sect. 4.3 we have given an intuitive account as to why the exit bonus must not be anticipated by the agents. Formally, the argument runs as follows. With an anticipated exit bonus, the first period wage must fulfill the following condition in order to still deter all uncommitted agents from applying:

$$
w_{1} \leq \underline{V}-b-\frac{q^{2} \bar{\gamma}^{2}}{2 \theta} \text {. }
$$

\footnotetext{
15 Note that Switzerland and other countries offer several forms of return assistance to refugees and other migrants (see e.g. Swiss Confederation 2015; Rijksoverheid 2015; or UK Border Agency 2014). The Swiss program for Tunisian asylum seekers, however, exposes most parallels to our study.

16 We also note an increased academic interest in pay-to-quit schemes, see e.g. the experimental study by Harris (2015).
} 
When the principal advertises the exit bonus, it becomes common knowledge that it will always be set such that at least the unmotivated agents with high outside opportunities leave after Period 1. As a result, the overall participation constraint of the committed agents collapses to:

$$
w_{1}+\frac{q^{2} \bar{\gamma}^{2}}{2 \theta}+n\left(q\left(w_{2}+\frac{\bar{\gamma}^{2}}{2 \theta}\right)+(1-q)\left(\bar{V}+\frac{b}{n}\right)\right) \geq(1+n) \bar{V} .
$$

Combined with Eq. (16), this gives us the following expression for the second period wage:

$$
\begin{gathered}
w_{2} \geq \frac{(1+n) \bar{V}}{n q}-\frac{w_{1}}{n q}-\frac{1}{n q} \frac{q^{2} \bar{\gamma}^{2}}{2 \theta}-\frac{1-q}{q}\left(\bar{V}+\frac{b}{n}\right)-\frac{\bar{\gamma}^{2}}{2 \theta} \\
\Rightarrow w_{2}=\frac{1+n q}{n q} \bar{V}-\frac{w_{1}}{n q}-\left(\frac{q}{n}+1\right) \frac{\bar{\gamma}^{2}}{2 \theta}-\frac{1-q}{n q} b,
\end{gathered}
$$

where the equality sign follows from profit-maximization by the principal. So, in comparison to the previously found expressions, the principal can indeed extract the expected value of exit bonus payments $\frac{1-q}{n q} b$ in the second period wage. Finally, the exit bonus needs to violate the continuation constraint of the committed unmotivated agents with high outside opportunities:

$$
b \geq n\left(w_{2}-\bar{V}\right)
$$

Using Eq. (17), it follows that:

$$
\begin{aligned}
b= & n\left(\frac{1+n q}{n q} \bar{V}-\frac{w_{1}}{n q}-\frac{q+n}{n} \frac{\bar{\gamma}^{2}}{2 \theta}-\frac{(1-q)}{n q} b-\bar{V}\right) \\
& \Longleftrightarrow b=\bar{V}-w_{1}-q(q+n) \frac{\bar{\gamma}^{2}}{2 \theta} .
\end{aligned}
$$

Setting Condition (16) binding, we get an expression for $w_{1}$ that we substitute:

$$
\begin{gathered}
b=\bar{V}-\underline{V}+b+\frac{q^{2} \bar{\gamma}^{2}}{2 \theta}-q(q+n) \frac{\bar{\gamma}^{2}}{2 \theta} \\
\Longleftrightarrow 0=\bar{V}-\underline{V}-n q \frac{\bar{\gamma}^{2}}{2 \theta} .
\end{gathered}
$$

That is, the exit bonus cannot be set optimally anymore. An announced exit bonus $b$ and the first period wage $w_{1}$ become perfect substitutes so that it is impossible to solve both adverse selection problems at once. 


\section{References}

Akerlof, G., \& Miyazaki, H. (1980). The implicit contract theory of unemployment meets wage bill argument. Review of Economic Studies, 47(1), 321-338.

Azariadis, C. (1975). Implicit contracts and underemployment equilibria. Journal of Political Economy, 83(6), 1183-1202.

Baily, M. (1974). Wages and employment under uncertain demand. Review of Economic Studies, 41(1), 37-50.

Benabou, R., \& Tirole, J. (2003). Intrinsic and extrinsic motivation. Review of Economic Studies, 70(3), 489-520.

Besley, T., \& Ghatak, M. (2005). Competition and incentives with motivated agents. American Economic Review, 95(3), 616-636.

Booth, A., \& Chatterji, M. (1989). Redundancy payments and firm-specific training. Economica, New Series, 56(224), 505-521.

Delfgaauw, J., \& Dur, R. (2007). Signaling and screening of workers motivation. Journal of Economic Behavior and Organization, 62(4), 605-624.

Ederer, F., Holden, R., \& Meyer, M. (2018). Gaming and strategic opacity in incentive provision. RAND Journal of Economics, 49(4), 819-854.

Edwards, J. (2014). This company pays employees \$25,000 to quit—no strings attached-even if they were just hired. Business Insider. Retrieved on November 30, 2015 from http://www.businessin sider.com/riot-games-pays-employees-25000-to-quit-2014-6? IR=T.

Foarta, D., \& Sugaya, T. (2019). The management of talent for innovation: Optimal contracting for selection and incentives. Stanford: Mimeo, Stanford GSB.

Fortune. (2012). Best companies to work for 2012. Retrieved September 17, 2013 from http://money .cnn.com/magazines/fortune/best-companies/2012/snapshots/11.html.

Geron, T. (2009). For Facebook and Zappos, two divergent views of its employees. The Wall Street Journal Blog. Retrieved on September 17, 2013 from http://blogs.wsj.com/venturecap ital/2009/10/29/for-facebook-and-zappos-two-divergent-views-of-its-employees/.

Glassdoor. (2013). Working at the Zappos family. Retrieved on September 17, 2013 from http://www. glassdoor.com/Overview/Working-at-The-Zappos-Family-EI_IE19906.11,28.htm.

Gordon, D. (1974). A neo-classical theory of Keynesian unemployment. Economic Inquiry, 12, 431-459.

Grossman, S. J., \& Hart, O. D. (1981). Implicit contracts, moral hazard and unemployment. American Economic Review, 71(2), 301-307.

Handy, F., \& Katz, E. (1998). The wage differential between nonprofit institutions and corporations: Getting more by paying less? Journal of Comparative Economics, 26(2), 246-261.

Harris, C. G. (2015). The effects of pay-to-quit incentives on crowdworker task quality. In Proceedings of the 18th ACM conference on computer supported cooperative work \& social computing (pp. 1801-1812).

Hart, O., \& Holmström, B. (1987). The theory of contracts. In T. Bewley (Ed.), Advances in economic theory; Fifth world congress (pp. 71-156). Cambridge: Cambridge University Press.

Hatton, T. J. (2004). Seeking asylum in Europe. Economic Policy, 19(38), 5-62.

Hsieh, T. (2010). Delivering happiness: A path to profits, passion, and purpose. New York, NY: Business Plus.

Inderst, R., \& Mueller, H. M. (2010). CEO replacement under private information. Review of Financial Studies, 23, 2935-2969.

Ito, T. (1988). Labor contracts with voluntary quits. Journal of Labor Economics, 6(1), 100-131.

Jeffries, A. (2012). Lot18 is straight-up paying unhappy employees to quit. Observer. Retrieved on November 30, 2015 from http://observer.com/2012/05/lot18-founder-offered-to-pay-unhappy-emplo yees-to-quit-today-and-six-of-them-did/.

Jehiel, P. (2015). On transparency in organizations. Review of Economic Studies, 82(2), 736-761.

Jeon, D.-S., \& Laffont, J.-J. (1999). The efficient mechanism for downsizing the public sector. The World Bank Economic Review, 13(1), 67-88.

Jovanovic, B. (1979). Job matching and the theory of turnover. Journal of Political Economy, 87(5), 972-990.

Kahn, C. (1985). Optimal severance pay with incomplete information. Journal of Political Economy, 93(3), 435-451. 
Lambert, R. A., \& Larcker, D. F. (1985). Golden parachutes, executive decision-making, and shareholder wealth. Journal of Accounting and Economics, 7(1-3), 179-203.

Lazear, E. P. (1979). Why is there mandatory retirement? Journal of Political Economy, 87(6), 1261-1284.

Lazear, E. P. (1981). Agency, earnings profiles, productivity, and hours restrictions. American Economic Review, 71(4), 606-620.

Lazear, E. P. (1990). Job security provisions and employment. Quarterly Journal of Economics, 105(3), 699-726.

Lazear, E. P. (2006). Speeding, terrorism, and teaching to the test. Quarterly Journal of Economics, 121(3), 1029-1061.

Levy, A., \& McLean, R. (1996). Optimal and sub-optimal retrenchment schemes: An analytical framework, working paper.

McFarland, K. (2008). Why Zappos offers new hires \$2000 to quit. Bloomberg Businessweek. Retrieved on September 17, 2013 from http://www.businessweek.com/stories/2008-09-16/why-zappos-offer s-new-hires-2-000-to-quitbusinessweek-business-news-stock-market-and-financial-advice.

NZZ. (2012). Asylwesen: Tunesische Asylbewerber reisen mit Rückkehrhilfe aus. Retrieved on September 17, 2013 from http://www.nzz.ch/aktuell/schweiz/tunesische-asylbewerber-reisen-mit-rueckkehrh ilfe-aus-1.17481896.

Parsons, D. O. (2019). The simple analytics of job displacement insurance. Journal of Risk and Insurance, 86(2), 351-380.

Pissarides, C. A. (2001). Employment protection. Labour Economics, 8, 131-159.

Rama, M. (1999). Public sector downsizing: An introduction. The World Bank Economic Review, 13(1), $1-22$.

Rijksoverheid. (2015). Terugkeer vreemdelingen. Retrieved on December 05, 2015 from http://www.rijks overheid.nl/onderwerpen/terugkeer-vreemdelingen.

Singh, J., Goolsby, J. R., \& Rhoads, G. K. (1994). Behavioral and psychological consequences of boundary spanning burnout of customer service representatives. Journal of Marketing Research, 31, 558-569.

Swiss Confederation. (2015). Rückkehrhilfe. Retrieved on December 05, 2015 from https://www.sem. admin.ch/sem/de/home/rueckkehr/rueckkehrhilfe.html.

Taylor, B. (2008). Why Zappos pays new employees to quit-And you should too. Harvard Business Review. Retrieved on September 17, 2013 from http://discussionleader.hbsp.com/taylor/2008/05/ wy_zappos_pays_new_employees_t.html.

Taylor, B. (2014). Why Amazon is copying Zappos and paying employees to quit. Harvard Business Review. Retrieved on November 30, 2015 from https://hbr.org/2014/04/why-amazon-is-copyingzappos-and-paying-employees-to-quit/.

The Economist. (2010). The trouble with sin as comparative advantage. Retrieved on September 17, 2013 from http://www.economist.com/blogs/democracyinamerica/2010/08/sinpoliticsandeconomicsne vada.

UK Border Agency. (2014). Voluntary assisted return and reintegration programme. Retrieved on December 05, 2015 from https:/www.gov.uk/government/publications/voluntary-assisted-retur n-and-reintegration-information-for-organisations/voluntary-assisted-return-and-reintegration-progr amme.

Von Thadden, E.-L., \& Zhao, X. (2012). Incentives for unaware agents. Review of Economic Studies, $79(3), 1151-1174$.

Witkin, J. (2012). How Zappos profits from the happiness business. Retrieved on September 17, 2013 from http://www.guardian.co.uk/sustainable-business/zappos-shoes-profits-happiness-business.

Yermack, D. (2006). Golden handshakes: Separation pay for retired and dismissed CEOs. Journal of Accounting and Economics, 41, 237-256.

Zappos. (2013a). Our benefits. Retrieved on September 17, 2013 from http://about.zappos.com/jobs/whywork-zappos/our-benefits.

Zappos. (2013b). Is it true that Zappos offers new-hires \$2000 to quit? Retrieved on September 17, 2013 from http://about.zappos.com/it-true-zappos-offers-new-hires-2000-quit. 